TAS Journal, vol. 5, n. 2, p. 88-92.

ISSN 2595-1521

JUNE 2020

gnmargarido@ifsp.edu.br

\title{
Valores encontrados em ensaios de influência da temperatura no rendimento em módulos fotovoltaicos comerciais
}

\author{
Margarido GN*§, Trigoso FBM§, Frajuca C* e Oliveira MM* \\ *Instituto Federal de Educação, Ciência e Tecnologia de São Paulo, IFSP, São Paulo, SP, \\ Brasil. §Universidade Federal do ABC, UFABC, Santo André, SP, Brasil.
}

Resumo. A temperatura de trabalho influencia no aproveitamento da energia solar pelos módulos fotovoltaicos, sendo que o aumento da temperatura ocasiona a diminuição da potência na geração fotovoltaica nos diversos materiais semicondutores utilizados nas células fotovoltaicas comerciais. O artigo relaciona valores de coeficientes de alteração de potência dos módulos fotovoltaicos em relação à temperatura para os principais materiais utilizados comercialmente encontrados em uma seleção de ensaios realizados em módulos fotovoltaicos. Os valores encontrados nos trabalhos apresentaram alguma divergência na variação da potência em relação à temperatura de trabalho.

Palavras-chave. Influência da temperatura, eficiência, módulos fotovoltaicos.

\section{Values found in tests of influence of temperature on performance in commercial photovoltaic modules}

\begin{abstract}
The working temperature influences the use of solar energy by photovoltaic modules, and the increase in temperature causes a decrease in power in photovoltaic generation in the various semiconductor materials used in commercial photovoltaic cells. The article lists values of power change coefficients of photovoltaic modules in relation to temperature for the main materials used commercially found in a selection of tests carried out on photovoltaic modules. The values found in the works presented some divergence in the variation of the power in relation to the working temperature.
\end{abstract}

Keywords. Influence of temperature, efficiency, photovoltaic modules. 
Introdução. A energia solar vem ganhando cada vez mais espaço na matriz energética mundial, não só pela busca de soluções para possíveis esgotamentos das já exploradas fontes energéticas tradicionais, mas também pela busca de fontes que proporcionem menos impactos ambientais. No cenário nacional a energia fotovoltaica vem ganhando mais destaque como opção na composição da matriz energética, proporcionando uma menor dependência energética das fontes hidráulicas e térmicas que acaba por gerar preocupações com riscos de que essas fontes possam não suprir a necessidade energética em determinadas épocas (7).

Os módulos fotovoltaicos são compostos por células montadas com uma junção de materiais semicondutores e realizam a conversão de energia luminosa em energia elétrica pela produção de elétrons e lacunas nas junções das células.

As células dos módulos fotovoltaicos comerciais geralmente utilizam silício, podendo ser utilizado o silício monocristalino ( $\mathrm{m}-\mathrm{Si}$ ), ou o silício policristalino (p-Si), adicionando material dopante para obter-se materiais semicondutores do tipo $\mathrm{p}$ e do tipo $\mathrm{n}$.

Alguns outros materiais também podem ser encontrados na fabricação de módulos, mas em menor escala de produção, tais como o silício amorfo (a-Si), telureto de cádmio (CdTe), e disseleneto de cobre índio e gálio (CIGS) (8).

Quando essas células são expostas à luz, é observada a geração de uma corrente elétrica no circuito. Porém, com o aumento da temperatura, ocorre uma diminuição da tensão elétrica. A corrente elétrica também é afetada nas células, apresentado uma elevação em correspondência ao aumento da temperatura, porém, essa alteração de corrente é muito pequena (Figura 1).

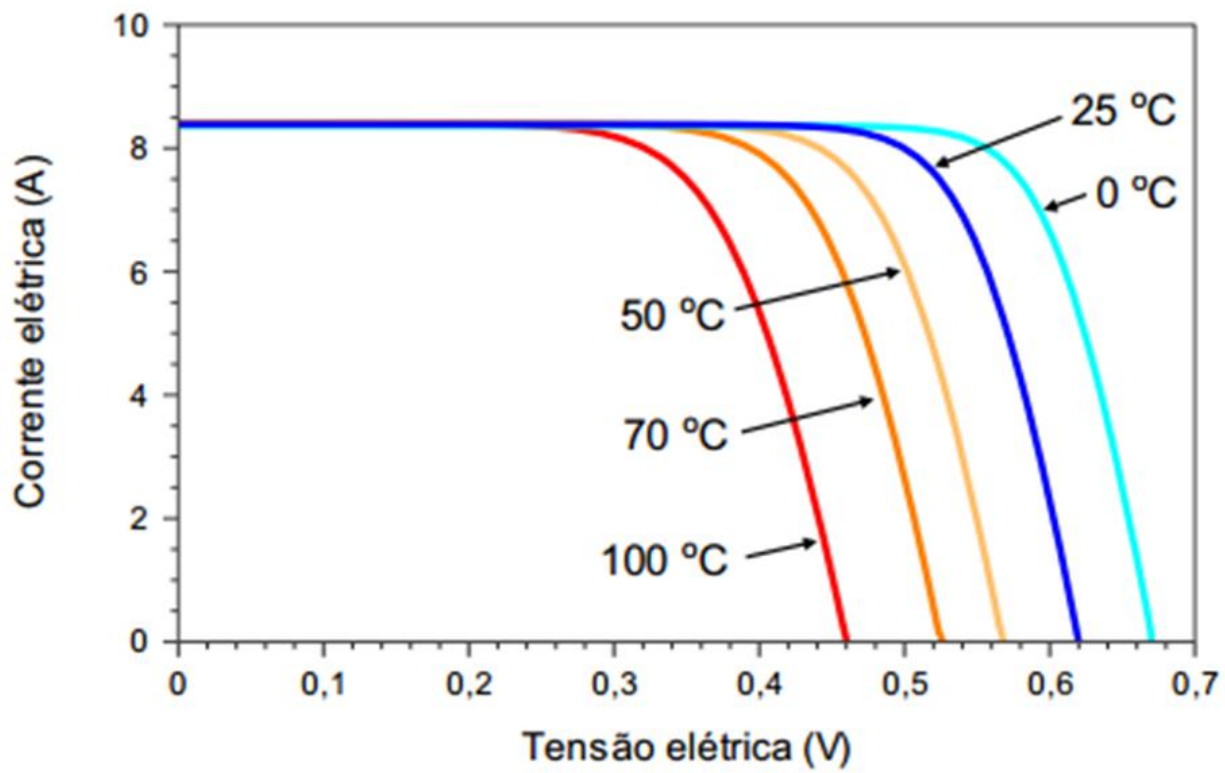

Figura 1. Relação de tensão e corrente em diversas temperaturas (8). 
Durante a operação dos módulos fotovoltaicos expostos à luz solar, é observado que a elevação da temperatura, no ambiente em que ficam expostos, irá ocasionar na diminuição da potência desenvolvida pela incidência energética solar nos processos de geração desses módulos (Figura 2).

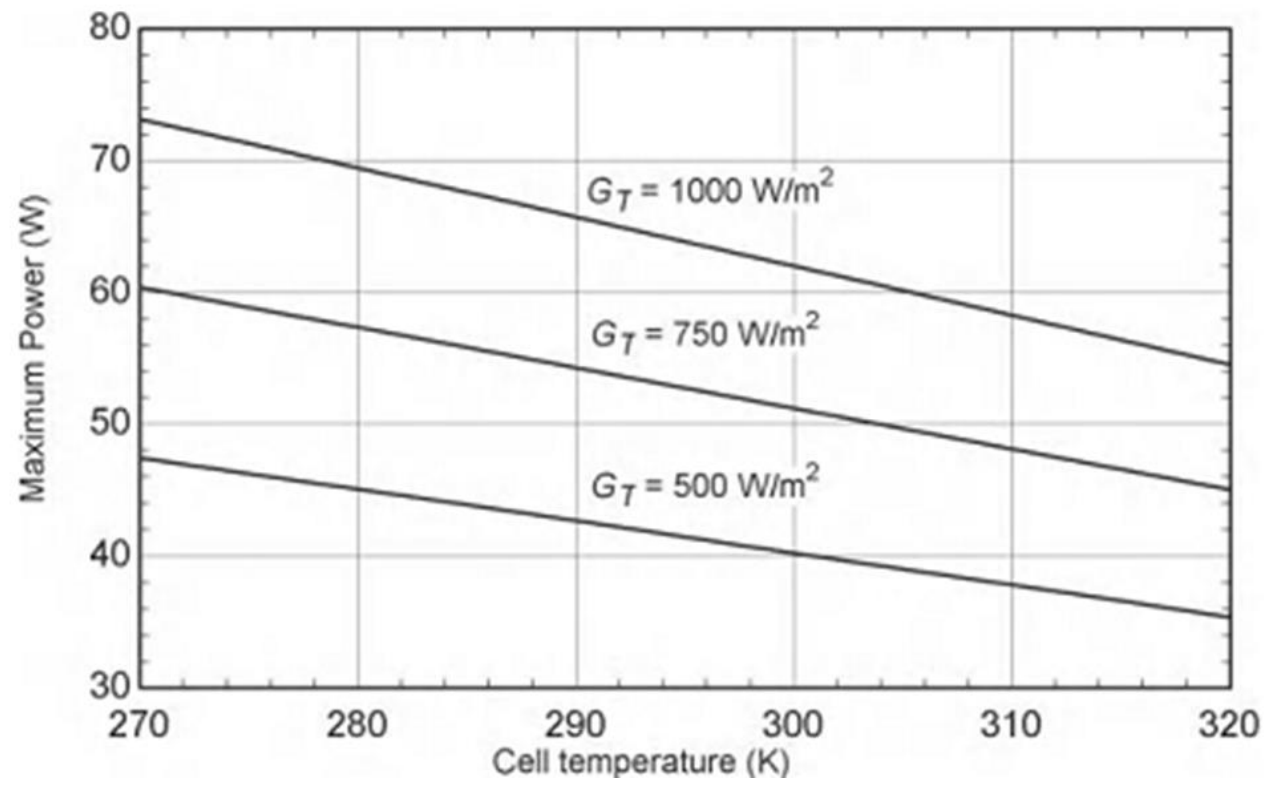

Figura 2. Relação da máxima potência desenvolvida pela célula para uma incidência energética solar em função da temperatura de trabalho (9).

Discussão e conclusões. Este trabalho apresenta valores de influência da temperatura na potência apresentada nos materiais mais utilizados comercialmente para a confecção de células para módulos fotovoltaicos.

Foram pesquisados artigos sobre ensaios de variação da eficiência de módulos fotovoltaicos em decorrência de variação da temperatura de trabalho. Foram selecionados cinco artigos (1-5, listados nas referências). A temperatura de referência considerada é a de $25^{\circ} \mathrm{C}$ (informada pelos fabricantes dos módulos fotovoltaicos).

Os artigos apresentavam valores de ensaios de potência dos diferentes materiais semicondutores em utilização nos módulos fotovoltaicos quando submetidos a diferentes temperaturas de trabalho, sem o envolvimento de testes de novas tecnologias de materiais para geração fotovoltaica ou materiais de apoio no processo como, por exemplo, materiais para isolação térmica (6). Os valores máximos e mínimos encontrados nos artigos foram organizados em uma tabela (Tabela 1). Observa-se certa variação dos valores encontrados: 
Tabela 1. Relação de alteração de potência pela temperatura

\begin{tabular}{|l|l|c|c|}
\hline \multicolumn{2}{|c|}{ Material } & $\begin{array}{c}\text { Mínimo } \\
{\left[\% /{ }^{\circ} \mathrm{C}\right]}\end{array}$ & $\begin{array}{c}\text { Máximo } \\
{\left[\% /{ }^{\circ} \mathrm{C}\right]}\end{array}$ \\
\hline Silício monocristalino & $\mathrm{m}-\mathrm{Si}$ & $-0,55$ & $-0,45$ \\
\hline Silício policristalino & $\mathrm{p}-\mathrm{Si}$ & $-0,56$ & $-0,39$ \\
\hline Silício amorfo & $\mathrm{a}-\mathrm{Si}$ & $-0,23$ & $-0,05$ \\
\hline Disseleneto de cobre índio e gálio & $\mathrm{CIGS}$ & $-0,43$ & $-0,33$ \\
\hline Telureto de cádmio & $\mathrm{CdTe}$ & $-0,17$ & $-0,10$ \\
\hline
\end{tabular}

Conclusão. A temperatura de trabalho influencia diretamente a potência dos módulos fotovoltaicos e são encontrados valores diversos de relação de alteração de potência nos ensaios encontrados em artigos, sendo indicados mais estudos sobre a influência da temperatura nos diversos materiais utilizados na tecnologia fotovoltaica, principalmente nos materiais menos utilizados comercialmente, com a finalidade de encontrar valores mais precisos da variação de potência nas diversas temperaturas de trabalho e possíveis soluções.

Agradecimentos. Registro agradecimento à organização da revista e ao programa de pósgraduação em energia da UFABC.

Divulgação. $\mathrm{O}$ autor não relata conflito de interesse neste trabalho. Este trabalho foi exibido em forma de pôster no XVIII Brazil MRS Meeting em setembro de 2019.

\section{Referências.}

(1) Zaini NH, et al. "The effect of temperature on a mono-crystalline solar PV panel", Energy Conversion (CENCON), 2015 IEEE Conference on. IEEE, 2015.

(2) Tobnaghi DM, Madatov R, Naderi D. "The effect of temperature on electrical parameters of solar cells," International Journal of Advanced Research in Electrical, Electronics and Instrument Engineering, vol. 2, pp. 6404-6407, 2013.

(3) Ishii T, et al. "Development of a practical method of estimating electric power from various photovoltaic technologies with high precision," Japanese Journal of Applied Physics56, 08MD05 (2017). 
(4) Dash PK, Gupta NC. "Effect of Temperature on Power Output from Different Commercially available Photovoltaic Modules" Int. Journal of Engineering Research and Applications, Vol. 5, January 2015, pp.148-151

(5) Khalis M, et al. "Effects of Temperature and Concentration Mono and Polycrystalline Silicon Solar Cells: Extraction Parameters", 2016 J. Phys.: Conf. Ser. 758012001

(6) Viana JL, et al. Filmes Finos de Alumina em substratos de alumínio 5052 por processo de Oxidação Eletrolítica à Plasma. TAS Journal, vol. 4, n. 3, p. 167-180, 2020.

(7) Acosta Zuñiga LS, De Andrade RJ. Perspectiva do Risco de Déficit de Energia Elétrica em 2018. TAS Journal Vol. 1, n. 3, p. 110-115, 2017.

(8) Pinho JT, Galdino MA (Orgs.). Manual de Engenharia Para Sistemas Fotovoltaicos. Rio de Janeiro: Grupo de Trabalho de Energia Solar, GTES- CEPEL - DTE - CRESESB, Edição revisada e atualizada, Março 2014, $530 \mathrm{p}$.

(9) Duffie JA, Beckman WA. Solar Engineering of Thermal Processes. Hoboken, New Jersey (USA): WILEY, 4rd. Edition, 2013, 910 p. 